\title{
A study on structural aspects of indoline-2, 3-dione-3-oxime: Experimental and theoretical approach
}

\author{
K. Laxmi \\ Department of Chemistry, Chaitanya Bharathi Institute of Technology(CBIT), Gandipet, Hyderabad -500 075
}

Email address:

katangurulaxmi@gmail.com

To cite this article:

K. Laxmi. A Study on Structural Aspects of Indoline-2, 3-Dione-3-Oxime: Experimental and Theoretical Approach. International Journal of Computational and Theoretical Chemistry. Vol. 1, No. 2, 2013, pp. 11-17. doi: 10.11648/j.ijctc.20130102.12

\begin{abstract}
Indoline-2,3-dione-3-oxime(IDOX) was synthesized and characterized by IR, mass and ${ }^{1} \mathrm{H}-\mathrm{NMR}$. The HyperChem 7.5 software was used for quantum mechanical calculations. The geometry optimization was carried out using $\mathrm{Ab}$ Initio method. The theoretical spectral data and QSAR parameters were generated with semi empirical single point AM1 method. The HOMO and LUMO frontier orbital energies were also computed for the optimized keto and enol forms of IDOX molecule. The experimental and theoretical spectral data are nearly comparable. The $\mathrm{pH}-$ metry studies indicated presence of one dissociable proton in IDOX.
\end{abstract}

Keywords: IDOX, Hyperchem 7.5 Software, QSAR

\section{Introduction}

Isatins (2,3-indoline-dione) are an important group of heterocyclic compounds which are biologically active and of significant importance in medicinal chemistry. A literature survey identified several isatin derivatives in the development phase as potential new drugs. Isatin derivatives that have been reported to show considerable pharmacological actions such as antimicrobial, anticancer, antiviral, anticonvulsant, antiinflammatory and analgesic ${ }^{2}$. Indoline-2,3-dione-3-oxime abbreviated as IDOX synthesized by the condensation of isatin with hydroxyl amine was found to have number of applications.

Epilepsy is a brain disorder that causes people to have recurrent seizure. A large number of populations of different age groups and sex are affected by this disease. The estimated number of people in 2011 with epilepsy would be 11.5 million in India. The number of new cases with epilepsy, each year would be close to half a million.

Therefore, studies have been carried out for designing of newer antiepileptic drugs with reduced neurotoxicity. Recently it has been found that isatin is a novel template for designing of new anticonvulsants $\mathrm{s}^{3-5}$.

Indoline-2,3-dione-3-oxime (Isatin -3-oxime)was found to have anticonvulsant activity ${ }^{6}$. Literature studies revealed that anticonvulsant screening of Indoline-2,3-dione-3oxime (IDOX)was performed by Maximal Electroshock (MES) model at dosage of 30, 100 and $300 \mathrm{mgkg}^{-1}$. IDOX was found to be active in the MES test at a lower dose of $100 \mathrm{mgkg}^{-1}$. This compound IDOX was also found to be more potent than standard drug sodium valproate.

In view of biological importance of Indoline-2,3-dione3-oxime (IDOX) ,in the present paper we report the structural aspects of IDOX in detail, both experimentally and theoretically using hyperchem 7.5 software.

\section{Experimental}

IDOX was prepared by refluxing an ethanolic solution $(50 \mathrm{ml})$ of isatin $(8.5 \mathrm{~g}, 0.057 \mathrm{M})$ and hydroxyl amine $(4.0 \mathrm{~g}, 0.028 \mathrm{~m})$ for $45 \mathrm{~min}$. The reaction mixture was cooled and left aside for $1 \mathrm{~h}$. A yellow crystalline product was obtained. The product was filtered and recrystallised from ethanol. Yield $75 \%$, m.p. $243^{\circ} \mathrm{C}$.Molecular weight of the ligand from mass spectra was found to be 162 .

\section{Physical Measurements}

IR spectrum of Indoline-2,3-dione-3-oxime (IDOX) was recorded in $\mathrm{KBr}$ phase on Perkin-Elmer Model no. $435 .{ }^{1} \mathrm{H}$ spectra of IDOX in $\mathrm{CDCl}_{3}$ and DMsO-d $\mathrm{d}_{6}$ using tetra methyl silane (TMS) as standard was recorded on Bruker WH $(270 \mathrm{MHz})$ spectrometer. Mass spectra of IDOX was recorded on Micro Mass V.G70-70H spectrometer operating at $70 \mathrm{ev}$ using direct inlet system.

The proton-ligand dissociation constant of IDOX was determined potentiometrically using Irwing -Rossoti $\mathrm{pH}$ 
titration technique. The $\mathrm{pH}$ measurements were made with a Digisun DI-707 digital $\mathrm{pH}$ meter, consisting of a combined glass electrode and calomel electrode.

The molecule IDOX was built by Hyperchem tools ${ }^{7-12}$, then the geometry optimization was carried out by employing Ab Initio optimized semi empirical single point AM1 method.
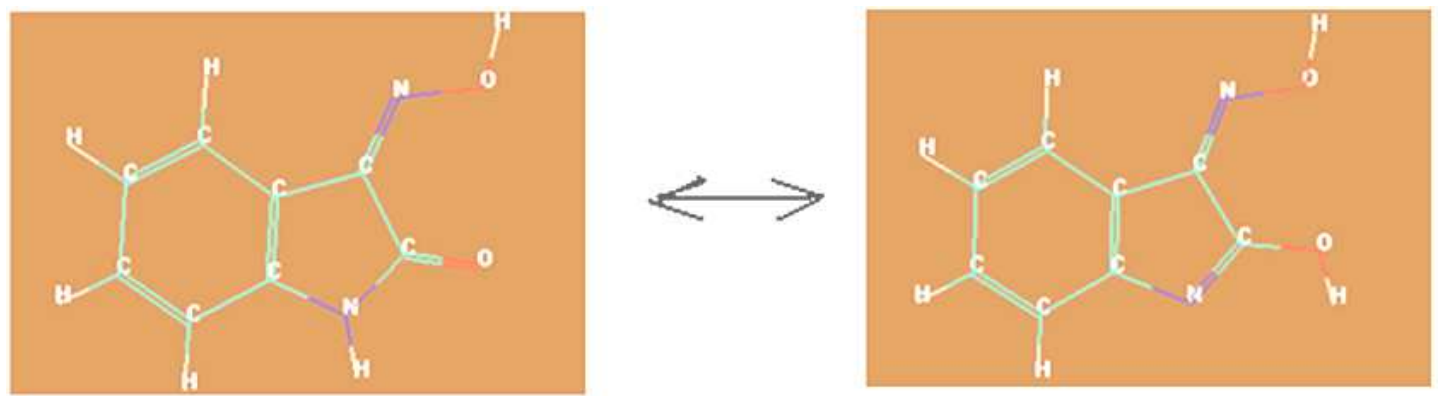

Fig. 1. (a) keto form of IDOX (b) enol form of IDOX
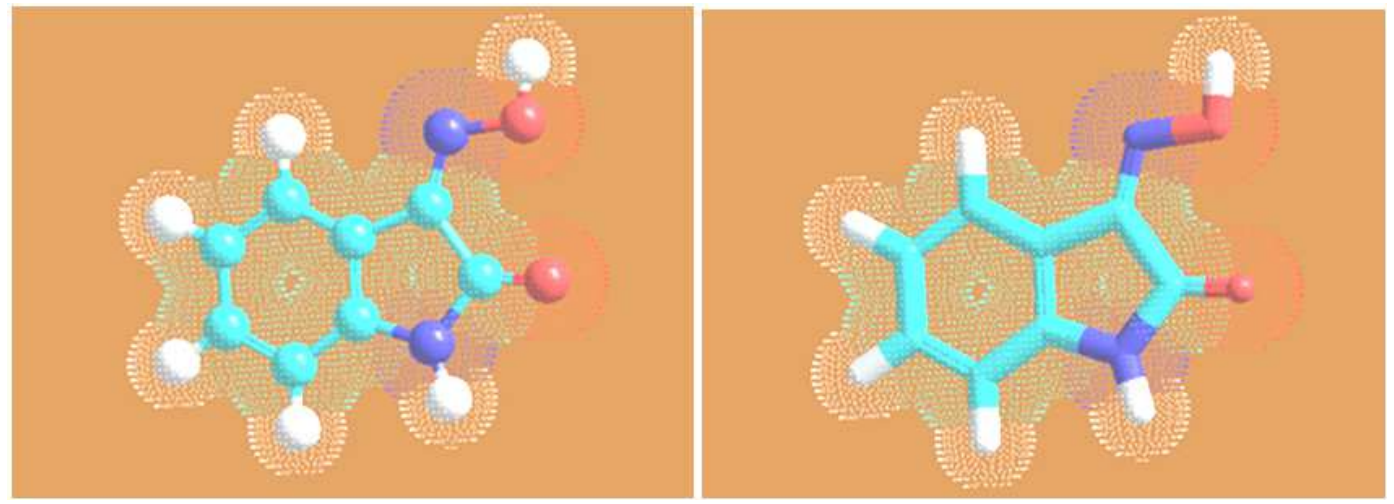

ball and cylinders tubes model

Fig.2. Structure of keto form of Indoline-2,3-dione-3-oxime(IDOX)

\section{Results and Discussion}

The HyperChem 7.5 software was used for quantum mechanical calculations to generate spectral data. After building molecule by Hyperchem tools, the geometry optimization was done using Ab Initio method(Figs.1 to 3).
The spectral data is generated with single point AM1 method approximation, for both keto and enol forms of IHA. The calculations are sensitive to the values of input parameters such as molecular geometry, bond lengths and values of coulombic, resonance and overlap integrals.
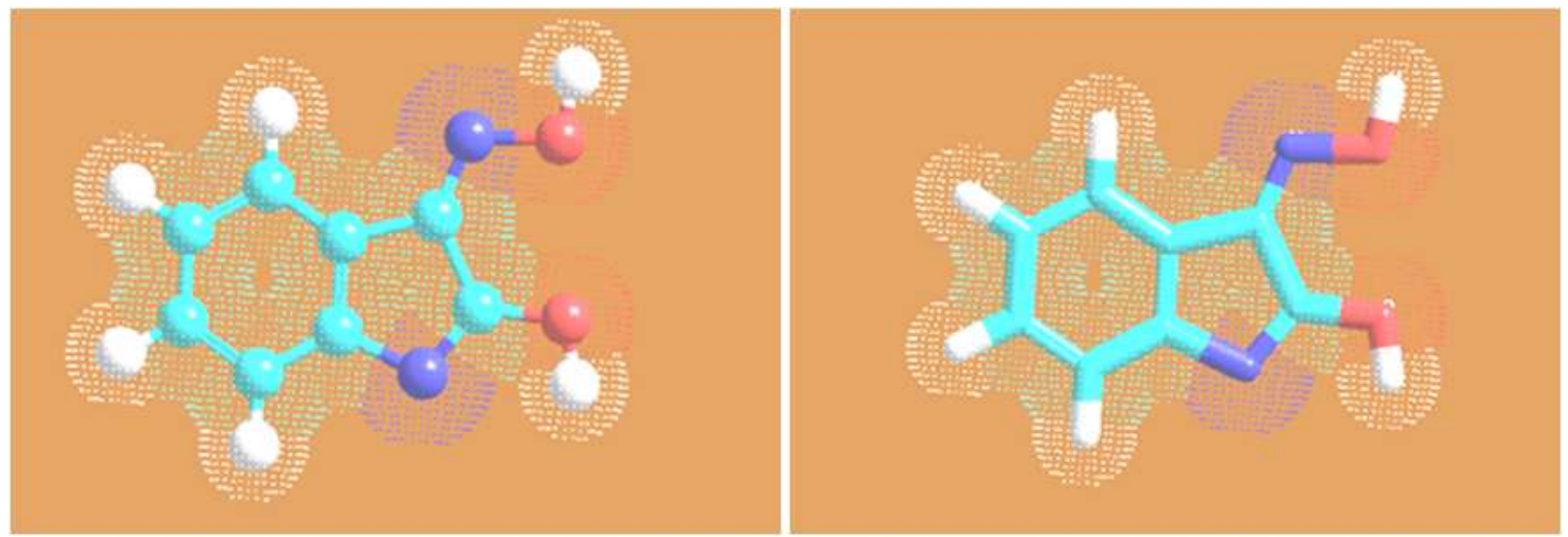

ball and cylinders model tubes model

Fig.3. Structure of enol form of Indoline-2,3-dione-3-oxime(IDOX)

From Potentiometric titrations it has been observed that there is only one dissociable proton present in the ligand IDOX. This is attributable to dissociation of proton from the ligand in enol form. From the calculations the $\mathrm{pKa}$ value of IDOX was found to be 10.00 in $70 \%(v / v)$ DMFwater medium. 


\section{Spectral Studies}

\subsection{IR Spectral Data of IDOX}

The experimental IR spectral data of the ligand IDOX is compared with the data generated for both keto and enol forms of IDOX by Ab Initio optimized semi empirical single point AM1 method(Figs.4,5).

VIBRATIONAL SPECTRUM OF IDOX keto form

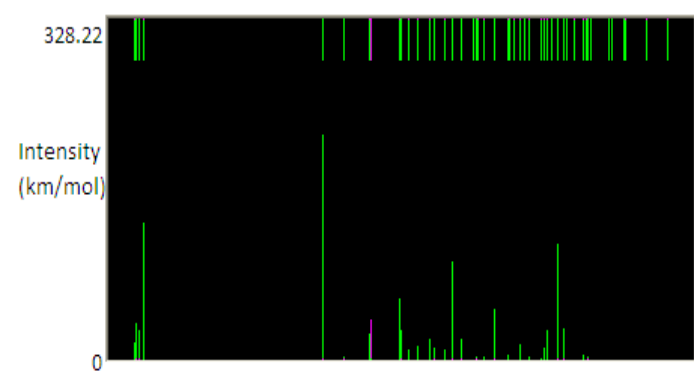

$3501 \mathrm{~cm}^{-1}$ wave number $\mathrm{cm}^{-1}$

Fig.4. IR spectrum of IDOX keto form
VIBRATIONALSPECTRUM OF IDOX enol form



Fig.5. IR spectrum of IDOX enol form

In IR spectrum ${ }^{13-17}$ of IDOX recorded experimentally the peaks appeared at $3180 \mathrm{~cm}^{-1}(\mathrm{vN}-\mathrm{OH}), 3050 \mathrm{~cm}^{-1}(\mathrm{vN}-\mathrm{H})$, $2896 \mathrm{~cm}^{-1}$ (vC-H), $1713 \mathrm{~cm}^{-1}(v \mathrm{C}=\mathrm{O})$. The IR spectral data obtained experimentally is in good agreement with the data generated by $\mathrm{Ab}$ Initio optimized semi empirical single point AM1 method(Table.1)

Table 1. IR Spectral data of IDOX (Experimental)*/ keto \& enol forms of IDOX

\begin{tabular}{|c|c|c|c|c|c|c|c|c|}
\hline & vN-OH & vN-H & v $\mathbf{C}=\mathbf{O}$ & vC-H & $\boldsymbol{v}_{\mathrm{C}=\mathbf{N}}$ & $\boldsymbol{v} \mathbf{c}={ }_{C}$ & v о-н & $\begin{array}{l}v \quad \text { N-H } \\
\text { bending }\end{array}$ \\
\hline IDOX* & $3180 \mathrm{~cm}^{-1}$ & $3050 \mathrm{~cm}^{-1}$ & $1713 \mathrm{~cm}^{-1}$ & $2896 \mathrm{~cm}^{-1}$ & $1633 \mathrm{~cm}^{-1}$ & $1823-1606 \mathrm{~cm}^{-1}$ & $1408 \mathrm{~cm}^{-1}$ & $1324 \mathrm{~cm}^{-1}$ \\
\hline IDOX keto & $3331 \mathrm{~cm}^{-1}$ & $3274 \mathrm{~cm}^{-1}$ & $1825 \mathrm{~cm}^{-1}$ & $3305--2133 \mathrm{~cm}^{-1}$ & $1647 \mathrm{~cm}^{-1}$ & $1839-1647 \mathrm{~cm}^{-1}$ & $1456 \mathrm{~cm}^{-1}$ & $1304 \mathrm{~cm}^{-1}$ \\
\hline IDOX enol & $3428 \mathrm{~cm}^{-1}$ & & & $3238--2238 \mathrm{~cm}^{-1}$ & $1693,1686 \mathrm{~cm}^{-1}$ & $1920-1786 \mathrm{~cm}^{-1}$ & $1479 \mathrm{~cm}^{-1}$ & \\
\hline
\end{tabular}

The mass spectrum ${ }^{13-17}$ of the title compound IDOX showed the molecular ion peak $\mathrm{M}^{+}$at $\mathrm{m} / \mathrm{z}$ 162(100) which is also base peak. This mass of IDOX is in good agreement with mass determined by QSAR studies for keto and enol forms of IDOX, which is recorded with single point approximation .

Mass spectral data of IDOX also indicates its composition is of $\mathrm{C}_{8} \mathrm{H}_{6} \mathrm{~N}_{2} \mathrm{O}_{2}$ which is also in agreement with elemental analysis data.(Found : $\mathrm{C}=59.62, \mathrm{H}=3.72$, $\mathrm{N}=17.39 \%$ while calcd $\mathrm{C}=59.25 ; \mathrm{H}=3.70 ; \mathrm{N}=17.28 \%$ )

\section{2. ${ }^{1}$ H NMR Spectral Data of IDOX}

To establish the existence of keto-enol tautomerism in Indoline-2,3-dione-3-oxime(IDOX) both keto and enol forms of IHA were built by using Hyperchem.

The experimental ${ }^{1} \mathrm{H}-\mathrm{NMR}$ spectral data of the ligand IDOX is compared with the data generated by $\mathrm{Ab}$ Initio optimized semi empirical single point AM1 method.

${ }^{1} \mathrm{H}-\mathrm{NMR}$ Spectral data of keto and enol forms of IDOX were recorded with single point approximation. The results are shown in figs 6,7 and Tables.2,3 as follows

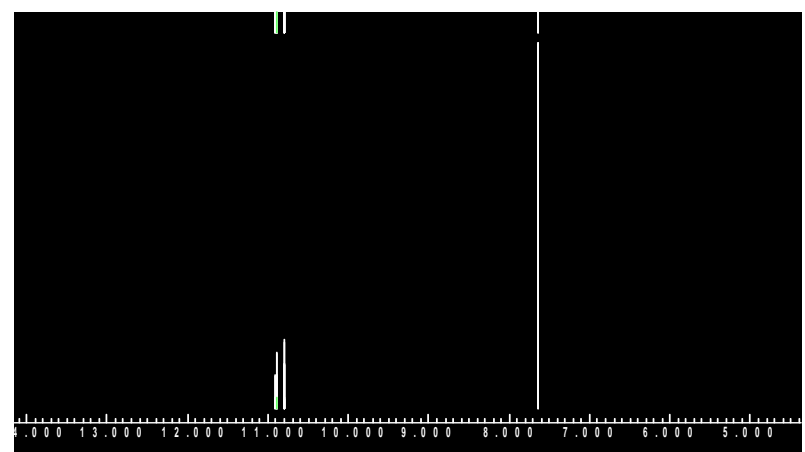

Fig. 6. ${ }^{1} H$-NMR spectrum of IDOX keto form

Table.2. ${ }^{I} H-N M R$ spectral data of IDOX keto form

\begin{tabular}{|c|c|c|c|c|c|c|}
\hline Index & $\begin{array}{l}1- \\
13(H)\end{array}$ & $\begin{array}{l}1- \\
14(\mathrm{H})\end{array}$ & $\begin{array}{l}1- \\
15(\mathrm{H})\end{array}$ & $\begin{array}{l}1- \\
16(H)\end{array}$ & $\begin{array}{l}1- \\
17(\mathrm{H})\end{array}$ & $\begin{array}{l}1- \\
18(\mathrm{H})\end{array}$ \\
\hline $\begin{array}{l}\text { Shieldi } \\
\text { ng }\end{array}$ & 16.305 & 16.305 & 16.305 & 16.305 & 13.054 & 13.154 \\
\hline Shift & 7.646 & 7.646 & 7.646 & 7.646 & 10.897 & 10.797 \\
\hline Tau & 2.354 & 2.354 & 2.354 & 2.354 & -0.897 & -0.797 \\
\hline
\end{tabular}




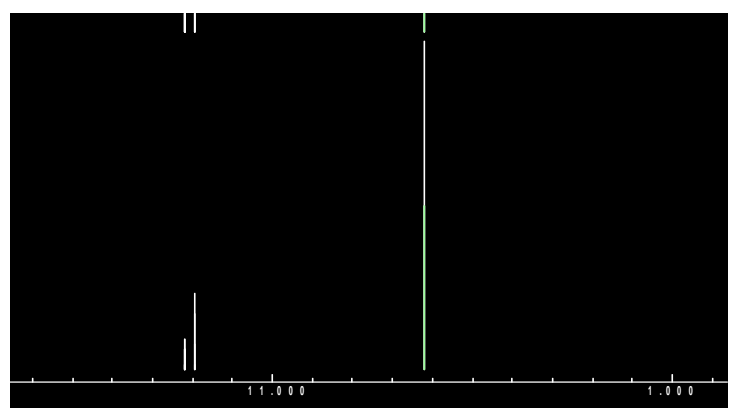

Fig. 7. ${ }^{1} H$-NMR spectrum of IDOX enol form

Table.3. ${ }^{1} H-N M R$ spectral data of IDOX enol form

\begin{tabular}{|c|c|c|c|c|c|c|}
\hline Index & $1-13(H)$ & $\begin{array}{l}1- \\
14(H)\end{array}$ & $\begin{array}{l}1- \\
15(H)\end{array}$ & $\begin{array}{l}1- \\
16(H)\end{array}$ & $\begin{array}{l}1- \\
17(\mathrm{H})\end{array}$ & $\begin{array}{l}1- \\
18(\mathrm{H})\end{array}$ \\
\hline $\begin{array}{l}\text { Shieldi } \\
\text { ng }\end{array}$ & 16.748 & 16.748 & 16.748 & 16.748 & 11.02 & 10.77 \\
\hline Shift & 7.203 & 7.203 & 7.203 & 7.203 & 12.931 & 13.181 \\
\hline Tau & 2.797 & 2.797 & 2.797 & 2.797 & -2.931 & -3.181 \\
\hline
\end{tabular}

Table.4. ${ }^{1}$ H NMR Spectral data of IDOX (Experimental)*/ keto \& enol forms of IDOX

\begin{tabular}{lllll}
\hline Compound & $\boldsymbol{\delta},=\mathbf{N}-\mathbf{O H}$ & $\boldsymbol{\delta}$-NH & $\begin{array}{l}\boldsymbol{\delta} \text { enolic }- \\
\text { OH }\end{array}$ & $\begin{array}{l}\boldsymbol{\delta}(\mathbf{C H})_{\text {aromati }} \\
\mathbf{c}\end{array}$ \\
\hline IDOX* & $10.59 \mathrm{ppm}$ & & $\begin{array}{l}13.2 \mathrm{ppm} \\
\text { enolic }-\mathrm{OH}\end{array}$ & $\begin{array}{l}7.30- \\
8.47 \mathrm{ppm}\end{array}$ \\
\hline IDOX keto & $10.797 \mathrm{ppm}$ & $\begin{array}{l}10.897 \\
\mathrm{ppm}\end{array}$ & & $7.644 \mathrm{ppm}$ \\
\hline IDOX enol & $13.181 \mathrm{ppm}$ & & $12.93 \mathrm{ppm}$ & $7.203 \mathrm{ppm}$ \\
\hline
\end{tabular}

${ }^{1} \mathrm{H}$ NMR spectrum ${ }^{13-17}$ of IDOX at $24{ }^{\circ} \mathrm{C}$ in $\mathrm{CDCl}_{3}+$ 3drops of DMSO-d6 shows peaks at $\delta 13.2 \mathrm{ppm}$ $(1 \mathrm{H}$,enolic $-\mathrm{OH}), \delta 10.59 \mathrm{ppm}(1 \mathrm{H},=\mathrm{N}-\mathrm{OH})$ and $\delta 7.30$ 8.47 ( 4H,Ar-H).

${ }^{1} \mathrm{H}-\mathrm{NMR}$ spectral data obtained experimentally is in good agreement with the data generated by $\mathrm{Ab}$ Initio optimized semi empirical single point AM1 method (Table.4).

The above spectral data recorded for both keto and enol forms of IDOX, is in good agreement with the experimental spectral data. This strongly confirms the existence of ketoenol tautomerism in IDOX.

\subsection{Quantitative structure activity relationship studies (QSAR studies)}

QSAR Properties allows calculation and estimation of a variety of molecular descriptors commonly used in Quantitative structure activity relationship (QSAR)studies ${ }^{18,19}$. Most of the methods were developed for and are primarily applicable to organic molecules. This analysis represents an attempt to relate structural descriptors of compounds with their physicochemical properties and biological activities.
Table 5. QSAR properties of Indoline-2,3-dione-3-oxime(IDOX)

\begin{tabular}{lll}
\hline QSAR properties & keto form of IDOX & $\begin{array}{l}\text { enol form of } \\
\text { IDOX }\end{array}$ \\
\hline Net charge & 0.00 & 0.00 \\
Surface area (approx) & $246.73^{\circ} \mathrm{A}^{2}$ & $233.75^{\circ} \mathrm{A}^{2}$ \\
Surface area (Grid) & $323.64^{\circ} \mathrm{A}^{2}$ & $323.09^{\circ} \mathrm{A}^{2}$ \\
Volume & $483.41^{\circ} \mathrm{A}^{3}$ & $487.02^{\circ} \mathrm{A}^{3}$ \\
Hydration energy & $-12.34 \mathrm{kcal}^{2} \mathrm{~mol}$ & $-16.07 \mathrm{kcal} / \mathrm{mol}$ \\
Log P & 0.39 & 1.43 \\
Refractivity & $46.19^{\circ} \mathrm{A}^{3}$ & $46.42{ }^{\circ} \mathrm{A}^{3}$ \\
Polarisability & $16.34^{\circ} \mathrm{A}^{3}$ & $16.47{ }^{\circ} \mathrm{A}^{3}$ \\
Mass & $162.15 \mathrm{amu}$ & $162.15 \mathrm{amu}$ \\
\hline
\end{tabular}

QSAR method included data collection, molecular descriptor selection correlation model development, and finally model evaluation. QSAR studies have predictive ability and simultaneously provide deeper insight. The main success of the QSAR method is the possibility to estimate the characteristics of new chemical compounds.

QSAR properties like surface area, volume, hydration energy, $\log \mathrm{P}$, refractivity, polarisability, mass, total energy etc. of keto and enol forms of IDOX were determined by single point AM1 method. (Table 5)

Table 6. Molecular properties of Indoline-2,3-dione-3-oxime(IDOX)

\begin{tabular}{|c|c|c|}
\hline $\begin{array}{l}\text { Molecular } \\
\text { properties }\end{array}$ & keto form of IDOX & enol form of IDOX \\
\hline Total energy & $-49784.78 \mathrm{kcal} / \mathrm{mol}$ & $\begin{array}{l}-49777.968 \\
\mathrm{kcal} / \mathrm{mol}\end{array}$ \\
\hline Binding energy & $-2004.237 \mathrm{kcal} / \mathrm{mol}$ & $-1997.422 \mathrm{kcal} / \mathrm{mol}$ \\
\hline Heat of formation & $20.61 \mathrm{kcal} / \mathrm{mol}$ & $27.43 \mathrm{kcal} / \mathrm{mol}$ \\
\hline Electronic energy & $-232715.51 \mathrm{kcal} / \mathrm{mol}$ & $\begin{array}{l}-231853.1875 \\
\mathrm{kcal} / \mathrm{mol}\end{array}$ \\
\hline Nuclear energy & $182930.73 \mathrm{kcal} / \mathrm{mol}$ & $\begin{array}{l}182075.2188 \\
\mathrm{kcal} / \mathrm{mol}\end{array}$ \\
\hline MP2 energy & $-421.3955078 \mathrm{kcal} / \mathrm{mol}$ & $\begin{array}{l}-419.8165283 \\
\mathrm{kcal} / \mathrm{mol}\end{array}$ \\
\hline Dipole moment & $3.16 \mathrm{D}$ & $1.2984 \mathrm{D}$ \\
\hline Dipole X & $-3.095 \mathrm{D}$ & $0.19053 \mathrm{D}$ \\
\hline Dipole Y & $0.5055 \mathrm{D}$ & $-1.28433 \mathrm{D}$ \\
\hline Dipole Z & $-0.0002 \mathrm{D}$ & $0.00000 \mathrm{D}$ \\
\hline RMS gradient & $24.63 \mathrm{kcal} /{ }^{\circ} \mathrm{A} \mathrm{mol}$ & $3.78 \mathrm{kcal} /{ }^{\circ} \mathrm{A} \mathrm{mol}$ \\
\hline Gradient X & $0.00061 \mathrm{kcal} /{ }^{\circ} \mathrm{A} \mathrm{mol}$ & $0.0000 \mathrm{kcal} /{ }^{\circ} \mathrm{A} \mathrm{mol}$ \\
\hline Gradient Y & $10.27 \mathrm{kcal} /{ }^{\circ} \mathrm{A} \mathrm{mol}$ & $\begin{array}{l}2.49713 \mathrm{kcal} /{ }^{\circ} \mathrm{A} \\
\mathrm{mol}\end{array}$ \\
\hline Gradient Z & $22.38 \mathrm{kcal} /{ }^{\circ} \mathrm{A} \mathrm{mol}$ & $\begin{array}{l}2.83741 \mathrm{kcal} /{ }^{\circ} \mathrm{A} \\
\mathrm{mol}\end{array}$ \\
\hline
\end{tabular}

According to the AM1 calculation binding energy of keto and enol forms IDOX is about $-2004.237 \mathrm{kcal} / \mathrm{mol}$ and$1997.422 \mathrm{kcal} / \mathrm{mol}$ respectively. The heat of formation of keto and enol forms IDOX is about $20.61 \mathrm{kcal} / \mathrm{mol}$ and 
$27.43 \mathrm{kcal} / \mathrm{mol} \mathrm{kcal} / \mathrm{mol}$ respectively and it is endothermic. Dipole moment of keto and enol forms IDOX is $3.16 \mathrm{D}$ and 1.2984 D. respectively. The trends of the molecular properties(Table.6) obtained by calculations are in good agreement with the experimental results ${ }^{7-12}$.

This analysis represents an attempt to relate structural descriptors of compounds with their physicochemical properties and biological activities.

\section{Quantum Chemical Studies}

Quantum chemical calculations have been widely used to study reaction mechanisms. Figs 8-11 shows the values of some quantum chemical parameters, namely the energy of the highest occupied molecular orbital $\left(E_{\mathrm{HOMO}}\right)$, energy of the lowest unoccupied molecular orbital $\left(E_{\mathrm{LUMO}}\right)$, the energy gap ( $E_{\mathrm{LUMO}}$-номо $)$. These values of $E_{\mathrm{HOMO}}, E_{\mathrm{LUMO}} \&$ $E_{\mathrm{LUMO}-\mathrm{HOMO}}$ for keto form of Indoline-2,3-dione-3oxime(IDOX) were found to be $-9.1405 \mathrm{eV},-0.7536139 \mathrm{eV}$ \& 8.3868 eV respectively. (Figs 8,9)

While the values of $E_{\text {Hомо }}, E_{\mathrm{LUMO}} \& E_{\mathrm{LUMO}}$-номо for enol form of Indoline-2,3-dione-3-oxime(IDOX) were found to be $-8.979 \mathrm{eV},-0.983402 \mathrm{eV} \& 7.9955 \mathrm{eV}$ respectively. (Figs 10,11)

The frontier molecular orbital energies (i.e., $E_{\mathrm{HOMO}}$ and
$\left.E_{\mathrm{LUMO}}\right)^{20,21}$ are significant parameters for the prediction of the reactivity of a chemical species. The $E_{\mathrm{HOMO}}$ is often associated with the electron donating ability of a molecule. The $E_{\mathrm{LUMO}}$ indicates the ability of the molecule to accept electrons.

Therefore higher value of $E_{\text {Номо }}$ indicates higher tendency for the donation of electron(s) to the appropriate acceptor molecule with low energy and empty molecular orbital. The highest occupied molecular orbitals are localized on the carbon atoms having double bond and on the $\mathrm{C}=\mathrm{N}$ bonds in the central part of the molecule. In Fig.8,10 the electron density occupying the molecular orbitals appears around $\mathrm{CO}, \mathrm{NH}$ and $\mathrm{C}=\mathrm{N}$ groups. These molecular orbitals represent the highest occupied molecular orbitals.

Figs.9,11 shows unoccupied molecular orbital regions that can accept electrons. $E_{\mathrm{LUMO}}$ as an electron acceptor represents the ability to obtain an electron. In keto form of IDOX the lowest unoccupied molecular orbitals are present mainly on the $\mathrm{C}=\mathrm{O}$ and $\mathrm{C}=\mathrm{N}$ bonds, while in enol forms of IDOX these orbitals are present on the $\mathrm{C}=\mathrm{N}$ bonds. But however LUMO's are delocalized through the acceptors and pi bridges. Therefore, from the lower value of $E_{\mathrm{LUMO}}$ of keto and enol forms of IDOX it is more apparent that the molecule would accept electrons.

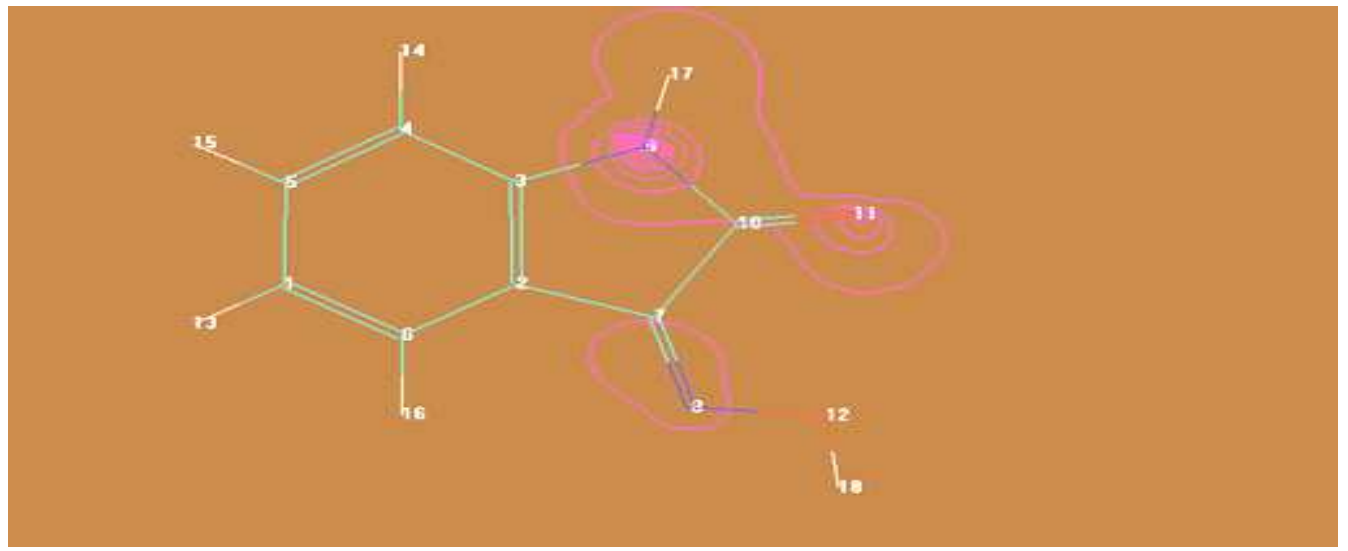

Fig 8. Highest occupied molecular orbital (HOMO) of keto form of Indoline-2,3-dione-3-oxime(IDOX) E= -9.1405 eV

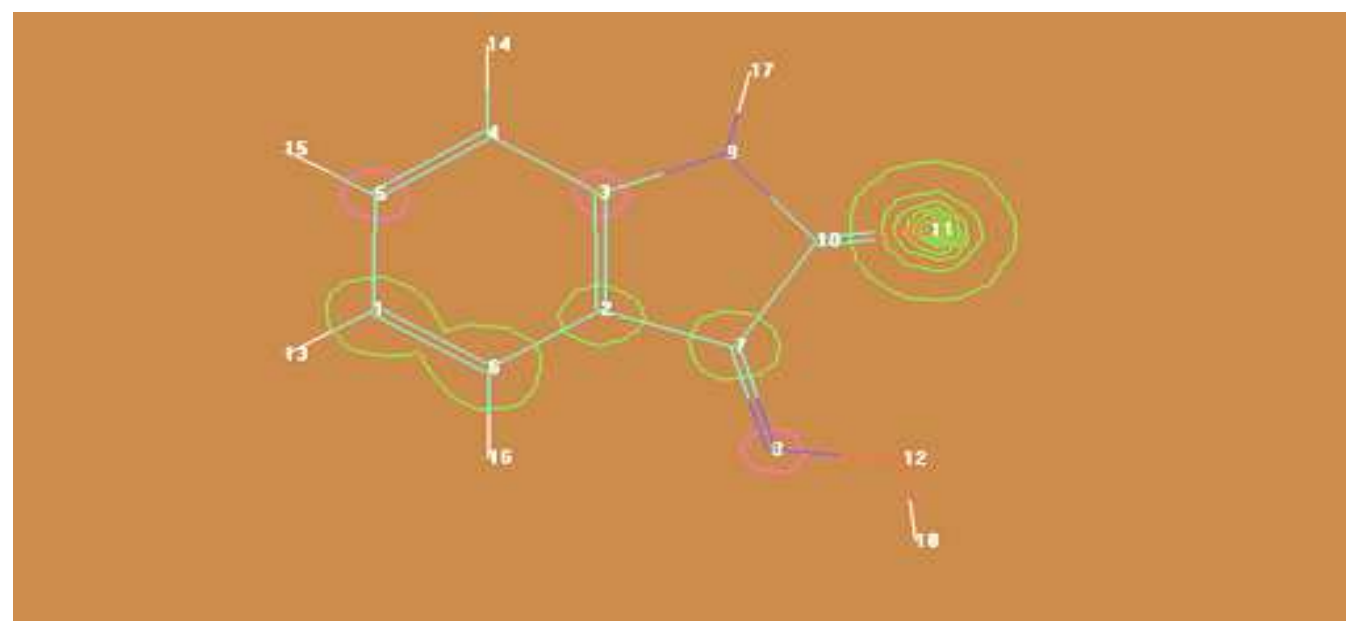

Fig 9. Lowest unoccupied molecular orbital (LUMO) of keto formof Indoline-2,3-dione-3-oxime(IDOX) E=-0.7536139 eV 


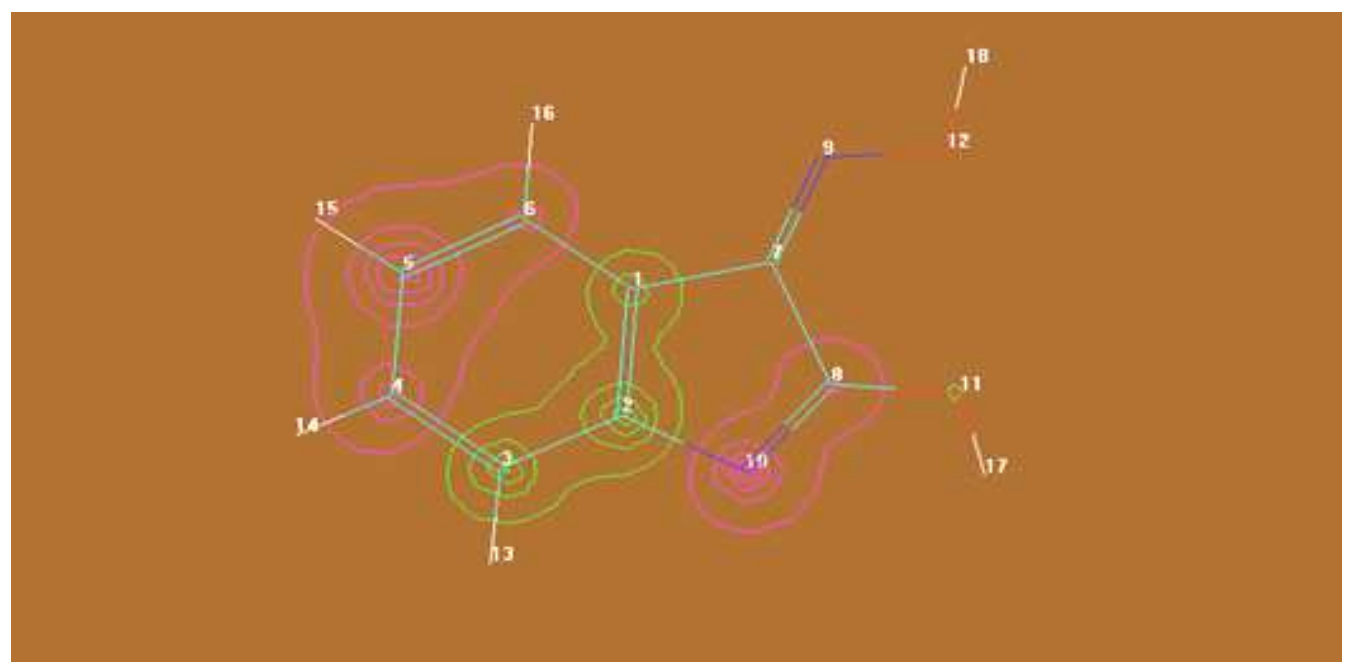

Fig 10. Highest occupied molecular orbital (HOMO) of enol form of Indoline-2,3-dione-3-oxime(IDOX). E= -8.979 eV

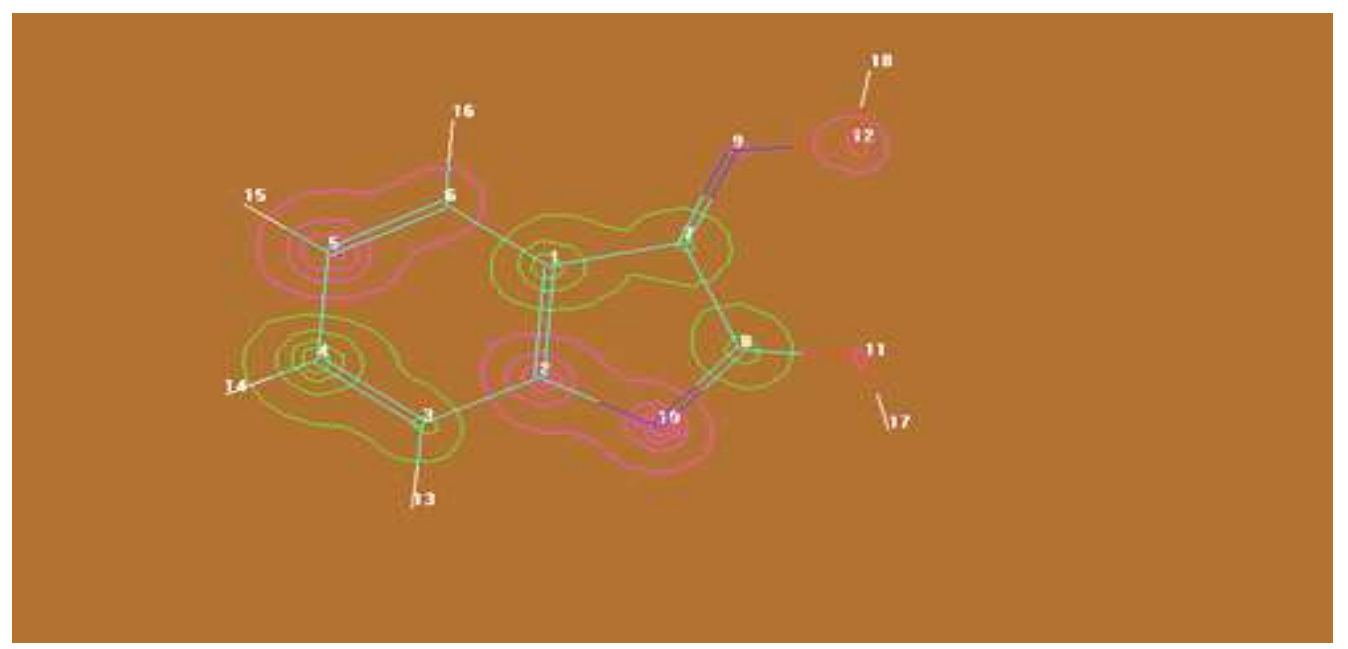

Fig 11. Lowest unoccupied molecular orbital (LUMO) of enol formof Indoline-2,3-dione-3-oxime(IDOX) E=-0.983402 eV

The frontier molecular orbital energy gap namely $E_{\mathrm{LUMO}}$ номо gap (Eg ) was calculated and it reveals that the energy gap reflects the chemical activity of the molecule. $E_{\text {LUMO- }}$ номо gap (Eg) energy separation was used as an index of

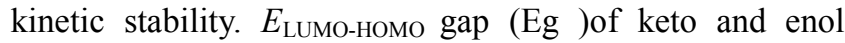
forms of IDOX molecule is about $8.3868 \mathrm{eV}$ and $7.9955 \mathrm{eV}$ respectively. Greater the $E_{\mathrm{LUMO}}$-Hомо gap ( $\mathrm{Eg}$ ) smaller is delocalization of electrons. ${ }^{7-12}$

\section{Conclusions}

The theoretical and experimental methods of study on the Indoline-2,3-dione-3-oxime (IDOX) compound is informative in understanding various physicochemical aspects of compounds. The HOMO and LUMO frontier orbital energies computed for the optimized molecules of keto and enol forms of IDOX indicated that the above compounds possess potential electron donor atoms. The computed IR , ${ }^{1} \mathrm{H}$ NMR data spectral data and QSAR parameters generated with semi empirical single point AM1 method for the above compound are nearly in good agreement with experimental data

\section{References}

[1] S. N. Pandeya, et al., Acta Pharm. (2005) 55 ,27-46

[2] Mitsikostas, D.D., Sanchez del Rio, et al Br J Pharmacol 1999, 127, 623 .

[3] S.N. Pandeya, A. S. Raja, et al., J. Pharm. Pharmaceut. Sci. (2002), 5(3), 266.

[4] S. Smitha, S. N. Pandeya, et al., Sci. Pharm. (2008), 76, 621.

[5] S. N. Pandeya, R. Kumar, et al., Asia J. Res. Chem., (2010), 3(3): 646

[6] S. N. Pandeya, et al., IJPI's Journal of Drug Chemistry (2012) Vol 2:8,1-7

[7] A.Broo, Per Lincoln, Ab- initio and Semi empirical Calculations of Geometry and Electronic Spectra of Ru complexes and Modeling DNA Binding, Inorg. Chem.,1997,36 , 2544- 2553.

[8] RK.Gilpin , Predicting ID NMR Spectra - HyperNMR, Analytical Chemistry.,1995, 67, Iss 17, A 541. 
[9] O.vanciuc, Hyperchem Release 4.5 for Windows, Journal of Chemical Information and Computer Sciences.,1996., 36 , Iss $3,612-614$.

[10] WR.Winchester and MP-Doyle, Hyperchem, Journal of the American Chemical Society., 1992, 114 , Iss 23 , 9243.

[11] W.Witanowski et al ,Solvent effects on the nitrogen NMR shieldings in oxadiazole systems, $J$.Magnetic Resonance .,1996, 120,Iss 2, 148-154

[12] (a)HyperChem Software, Hypercube Inc Florida Science and Technology Park,1115 NW, $4^{\text {th }}$ Street,Gainesvilla,Florida,326001,USA.,2006,12

(b)HyperChem ${ }^{\circledR}$ Computational Chemistry, Part 1 \&Part 2 Hypercube, Inc. Publication ,HC50-00-03-00,1996,21-67

[13] A.Padmaja,K.Laxmi and Ch.Sarala Devi, J.Indian Chem. Soc., 2011,88, 183-187

[14] A.Padmaja, Aliya Begum,P.Raghavaiah and Ch.Sarala Devi,Indian Journal of Chemistry., 2011,50B, 326-329
[15] K.Laxmi,G.Bhargavi,B.Sireesha and Ch.Sarala Devi, Bull.Chem.Soc.Ethiop.,2006,20(1),161-166

[16] G.Srinivas Reddy,B.Sireesha,K.Laxmi and Ch.Sarala Devi, Bulletin of Pure and Applied Sciences.,2005,24C,(No.1-2), 57-61

[17] K.Laxmi, and Ch.Sarala Devi, J.Electrochem Soc.,India.,2000 ,49-2, 85-88

[18] C,Hansch, A.Leo and DH Hoekman, Exploring QSAR , Fundamentals and applications in Chemistry and Biology, American Chemical Society Washington ,DC, USA:1995

[19] A.K.Srivastava, M.Jaiswal, Archana and A. Srivastava, Oxid. Commun.,2009,32,55

[20] T.Kar, S.Scheiner and A.B.Shannigrahi ,J.Phys Chem., 1998, A102, 5967-5973

[21] A.Shafiee ,M.Matsallah and M.Yahaya , Sains Malaysiana ,2011, 40(2), 173-176 